\title{
REGULAÇÃo SANITÁRIA POR UM ENFOQUE JUDICIAL. O HORÁRIO DE FUNCIONAMENTO DE FARMÁCIAS E DROGARIAS NO ESTADO DE SÃo PAULO ${ }^{(*)}$
}

\author{
SANITARY REGULATION BY A JUDICIAL VIEW. \\ THE SCHEDULE OF FUNCTIONING OF PHARMACIES \\ AND DRUGSTORES IN THE STATE OF SÃO PAULO - BRAZIL
}

Ana Maria A. Figueiredo de Souza ${ }^{(*)}$
Filipe Cleodon Cordeiro de Medeiros
Silvia Badim Marques
$\left({ }^{(* . *)}\right.$

\begin{abstract}
RESUMO
O presente trabalho tem como base a visão judicial da regulação sanitária no Estado de São Paulo no tocante à abertura e funcionamento de farmácias e drogarias em finais de semana e feriados fora dos horários previstos em lei. Essa é uma questão que enseja a atuação da Administração Pública por meio da Vigilância Sanitária e seus respectivos representantes legais e pode ocasionar autuações e fechamentos irregulares desses estabelecimentos. A função de regulação no âmbito da ação sanitária tem assumido, nos dias atuais, a agregação de sentido para além da regulamentação ou controle do risco sanitário, ampliando significação no campo econômico.
\end{abstract}

\section{Palavras-chave}

Regulação, Funcionamento, Farmácias e Drogarias.

(*) Este trabalho foi orientado pela Profa. Dra. Sueli Gandolfi Dallari, realizado como uma das avaliaçōes da Disciplina HSP-5730, "Aspectos Jurídicos e Legais da Politica, do Planejamento e da Administração em Saúde”, da Pós-Graduação da Faculdade de Saúde Pública da USP, 2002.

(") Médica sanitarista, Mestra em Medicina Preventiva, USP, 1997.

("**) Aprimorando FUNDAP em Direito Sanitário, USP, 2002.

(***) Advogada, mestranda em Saúde Pública, USP, 2002. 


\section{ABSTRACT}

The present work has as principal element the judicial view of sanitary regulation in the State of São Paulo - Brazil, concerning the opening and functioning of pharmacies and drugstores besides the schedule due to the law. This is a question that demands the actuation of the Public Administration through the Sanitary Vigilance and its respective agents and may cause irregular notification and closing of these establishments. The function of regulation in the sanitary action ambit has assumed, in the actual days, the aggregation of meaning beyond the rules or the control of sanitary risks, increasing meaning in the economic field.

\section{Key-word}

Regulation, Functioning, Pharmacies and Drugstores.

\section{INTRODUÇÃO}

O presente trabalho objetiva analisar a aplicação do Direito no âmbito de questões sanitárias relevantes na sociedade brasileira contemporânea. $O$ Direito Sanitário possui um papel fundamental para a compreensão do campo de atuação da vigilância sanitária, agindo como operador da norma sanitária dentro do Sistema de Saúde.

O medicamento pode ser identificado como uma dessas questões sanitárias de relevância no contexto da política de saúde, tanto pela perspectiva do acesso quanto da segurança. Por outro lado, como importante produto de consumo, seus locais de comercialização (farmácias e drogarias) têm vinculações estreitas com questões de política econômica e de desenvolvimento científico e tecnológico, presentes de forma expressiva nos diversos meios de comunicação.

A visão judicial da regulamentação sanitária no Estado de São Paulo, no tocante à abertura e funcionamento de farmácias e drogarias, em finais de semana e feriados fora dos horários previsto em Lei, foi escolhida como uma possibilidade de estudo da relação entre as decisões do Poder Judiciário e as atuações da Vigilância Sanitária.

A função de regulação no âmbito da ação sanitária tem assumido nos dias atuais um sentido mais destacado no campo econômico ao lado do controle do risco sanitário. Essa função tem gerado um debate, ainda sem consenso, pois o conceito de regulação no âmbito do setor, indispensável para a análise do papel do Estado Contemporâneo, não tem sido apreendido 
pelos profissionais que atuam no setor, em um contexto histórico que considere a evolução do Direito Moderno ao Direito Contemporâneo.

Para dar viabilidade ao objeto do presente estudo, foram analisadas sentenças proferidas por juizes da Fazenda Pública do Estado de São Paulo, cujo tema é a abertura de farmácias e drogarias aos sábados, domingos e feriados fora do horário legal de plantão, e que tem como autoridade impetrada a Vigilância Sanitária do Estado e do Município e seus respectivos representantes legais.

\section{A QUESTÃO DO FUNCIONAMENTO DE FARMÁCIAS E DROGARIAS NA PERSPECTIVA DO RISCO SANITÁRIO}

A chamada revolução científica, com os avanços dos conhecimentos da fisiologia e da patologia a partir do século XVII, graças aos novos paradigmas que foram sendo instituídos pelas contribuições de Descartes, Copérnico, Galileu, Kepler, Newton e muitos outros, gera a nova concepção do mundo, onde os princípios holísticos com os quais a medicina atuava desde a Grécia Antiga são substituídos. O organismo humano será conhecido em profundidade pelas suas partes, e a especialização se torna inevitável e progressiva em segmentações sucessivamente menores e detalhadas. Capra, em $1986^{(1)}$, ao examinar tal sucessão de mudanças, modelo explicativo e operativo da medicina, chama a atenção para o fato de que o conceito de universo orgânico, vivo e espiritual, foi substituido pela noção do mundo como máquina, instituindo-a como metáfora na era moderna.

O medicamento reaparece no mundo moderno com nova significação do objeto mágico que os "fármacos" ocuparam até então, participando da técnica passivel de solucionar todos os problemas no modelo biomédico com que a prática médica passa a atuar. Na sociedade capitalista o medicamento constitui parte da função simbólica do consumo como categoria histórica, sociológica e econômica, constituindo o que os estudiosos do campo chamam de "fenômeno da medicalização"(2).

Aos medicamentos passam a ser atribuídas funções que ultrapassam a farmacológica propriamente; são signos com representações de domínio sobre sintomas trazendo sensação de segurança e conforto. Como objeto técnico, asseguram nessa perspectiva a eficácia, e a novidade terapêutica é associada freqüentemente à competência. Tais circunstâncias reeditam a preocupação que já era antiga com o prejuízo aos pacientes que os "fárma-

(1) CAPRA, F. O Ponto de Mutação. Sāo Paulo: Cultrix, 1986.

(2) BARROS, José Augusto Cabral. Propaganda de Medicamentos. Atentado à Saúde? São Paulo-

Rio de Janeiro: HUCITEC - SOBRAVIME, 1995. 
cos" podem causar, agora sob a denominação de iatrogenia, quando induzida pela intervenção médica, ou a automedicação, quando pelo próprio indivíduo. Essas novas preocupações vão se relacionar aos riscos, ou prejuizos aos indivíduos, sendo formalizadas em normas sanitárias para todas as fases do ciclo do medicamento: da produção, da distribuição, da comercialização, da prescrição e do uso.

Neste contexto surgem as normas sanitárias relacionadas às fases de distribuição, acondicionamento e estocagem, distribuição, dispensação, onde as farmácias e drogarias são os "estabelecimentos comerciais" especiais, com serviços ligados à prestação da atenção à saúde e como tais sujeitas às referidas normas.

O conjunto dos riscos associados aos medicamentos no âmbito do seu ciclo de produção-consumo, que acontece relacionado ao funcionamento da farmácia e drogaria, pode ser agrupado por características especificas. Assim, avaliada a base legal pertinente, na fase da comercializaçãc e dispensação que acontece nesse âmbito, identificamos quatro grupos de riscos:

- Riscos relacionados à prática de preparação de medicamentos, as chamadas fórmulas magistrais, que são manipuladas nos espaços fisicos das farmácias, sob prescrição por médicos para individuos ou circunstâncias especificas. Tais circunstâncias envolvem a necessidade da presença de profissional habilitado para a prática da manipulação, o farmacêutico, bem como condições físico-ambientais e de equipamentos que a norma disciplina;

- Riscos relacionados às condições de acondicionamento, guarda, transporte dos medicamentos em dado estabelecimento;

- Riscos relacionados à dispensação de medicamentos, circunstâncias que se associam às práticas da automedicação ou prescrição por profissionais não habilitados para tal ação;

- Riscos relacionados à não-observância de prazos de validade e registros.

\section{A QUESTÃO DO FUNCIONAMENTO DE FARMÁCIAS E DROGARIAS NA PERSPECTIVA DO DIREITO SANITÁRIO}

Do Direito Administrativo do Estado Moderno ao Estado Contemporâneo

O Direito Administrativo do Estado Moderno nasce com a revolução burguesa ocorrida no final do século XVIII, e, assim sendo, é fruto dos ideais 
que regeram tal revolução. A classe burguesa, detentora do poder econômico da época, sob o pretexto de alcançar um "governo do povo para o povo" e destituir uma forma de governo absolutista, onde o Estado se confundia com a figura do monarca e regia todas as formas de relações entre os indivíduos, não havendo espaço para qualquer tipo de participação popular, busca com êxito a detenção do poder político e com ele o enfraquecimento do Estado perante os interesses individuais, preconizando "a intervenção mínima do Estado na vida social, considerando a liberdade contratual um direito natural dos indivíduos".

"Sob a influência do jusnaturalismo, outros direitos naturais foram sendo proclamados, sobretudo no âmbito econômico, como a propriedade, visando impedir qualquer interferência do Estado no sentido de criar algum condicionamento à manutenção ou ao uso de bens, ou alguma restrição aos termos de qualquer contrato." ${ }^{\prime(3)}$ Assim nasce o Estado Liberal Moderno, no qual qualquer restrição ao individual em favor do coletivo era vista como uma forma ilegítima de atuação do Estado.

Dessa forma, o Estado passa a atuar como mero coadjuvante na ordem social e econômica, intervindo apenas para garantir a segurança pública e as situações já estabelecidas pelos individuos, o que coincidiu, propositadamente, com os interesses dos grandes proprietários e comerciantes, quais sejam: a ausência de empecilhos em suas negociações e a acumulação de capital.

Para garantir que o Poder do Estado continuasse à margem da Liberdade Individual, o Estado moderno rege-se pelos principios da Separação dos Poderes (divisão do Poder do Estado entre Legislativo, Executivo e Judiciário, com funções diversas e autônomas - quanto maior a divisão de funções do Estado menor será o risco de uma forma ditatorial de Governo) e da Estrita Legalidade (nenhum cidadão é obrigado a fazer ou a deixar de fazer algo senão em virtude da Lei, a qual expressa, em tese, a vontade geral dos cidadãos).

Nesse contexto surge então o Direito Administrativo Moderno, com a missão de estruturar juridicamente a ação administrativa do Estado. $O$ direito administrativo do Estado Moderno, ao limitar a ação do Estado, acaba deixando a ação da Administração Pública contida entre princípios legais e diretrizes estáticas, havendo pouco espaço para uma atuação coordenada e com mais amplitude para atender as diversas demandas sociais que surgem de forma desvinculada da Lei.

Em meados do século XIX, começam a aparecer diversas crises decorrentes das grandes desigualdades sociais surgidas pelo fortalecimento

(3) Dallari, Dalmo de Abreu. Elementos de Teoria Geral do Estado. São Paulo: Saraiva, 2000, p. 275. 
da classe economicamente mais forte, aliada à ausência de atuação do Estado para proteger os economicamente mais fracos. Com o advento da revolução industrial essa situação se agrava. O excesso de oferta de mão-deobra e a concentração do poder econômico e político nas mãos da classe burguesa fazem surgir uma situação social desumana, onde as massas urbanas (proletariado) passam a viver com uma remuneração irrisória e em péssimas condições de trabalho e habitação.

A partir das primeiras décadas do século $X X$ esse quadro torna-se insustentável e leva o Estado a intervir diretamente nas atividades sociais e econômicas, ainda sob as amarras da estruturação do Estado Moderno pela revolução burguesa. O Estado passa então a procurar uma forma de Estado do Bem-Estar Social, intervencionista, a partir da estruturação do Estado Liberal Burguês, sustentado pela prevalência das garantias individuais sobre as coletivas.

No século $X X$ e neste início do século $X X I$, com a ocorrência de duas grandes guerras mundiais, com a crise econômica mundial dos anos 70 e com o atual e crescente processo de abertura de fronteiras entre os países (comerciais, culturais, políticas), conhecido como "globalização", faz-se necessário rever o papel do Estado (ainda atrelado aos moldes do Estado Moderno burguês) no atual contexto social e econômico e conseqüentemente da Administração Pública (regulada e embasada pelo Direito Administrativo), no intuito de adequá-la às necessidades contemporâneas.

É importante destacar que a Administração Pública dentro do Estado é "a máquina que o faz funcionar, o aparelho que realiza ou executa a atividade material no seu âmbito interno"(4), sendo, portanto indispensável sua devida estruturação, de modo a atender as demandas sociais e econômicas, para que as ações do Estado sejam eficazes.

\section{Da regulação no Estado Contemporâneo}

O Direito Administrativo, devido à necessidade de uma atuação do Estado mais ampla e mais condizente com as necessidades da sociedade, passa então a procurar novas formas de atuação da Administração Pública, desprovidas do rigor formal imputado pelo Estado Liberal burguês. Surge então o conceito de regulação, buscando alternativas para equilibrar o sistema, uma vez que os seus instrumentos, estritamente previstos, não são mais suficientes para proporcionar soluções adequadas e eficazes aos problemas existentes no Estado Contemporâneo.

(4) Bucci, Maria Paula D. Direito Administrativo e Políticas Públicas. Săo Paulo: Saraiva, 2002, p. 2. 
A contenção existente à atuação da Administração Pública, incluindo sua ação discricionária ${ }^{(5)}$, necessita ser revista, uma vez que os moldes legais que embasam a atuação estatal acabam perdendo eficácia quando são implementados, visto a impossibilidade de adequá-los exatamente às necessidades encontradas na realidade no momento de sua implementação.

A Administração do Estado passa então a experimentar a implantação de políticas públicas, consistentes em metas coletivas e previamente estabelecidas, em busca de satisfazer o interesse público de determinada área social. Essas diretrizes baseiam então a escolha e a atuação do Administrador e se encontram entre a Lei e a aplicação prática do ato administrativo.

"Hoje, o desafio da atuação estatal, num Estado como o brasileiro, é exatamente o da coordenação para a execução das políticas, pois o que se tem verificado é que há uma profusão de leis e normas de cunho declaratório (ou meramente retórico) que não encontram eficácia, uma vez que seu 'poder coativo' se perde no espaço intraestatal entre os momentos da decisão e da execução." ${ }^{\text {"(6) }}$

As agências reguladoras têm representado um papel de destaque nesse contexto. $\mathrm{Na}$ área da saúde coletiva, em especial no âmbito da Vigilância Sanitária, podemos citar a Agência Nacional de Vigilância Sanitária ANVISA, criada em 26 de janeiro de 1999 pela Lei n. 9.782, como exemplo de um órgão criado para viabilizar a implementação de políticas públicas nesta área. A citada Agência é uma autarquia sob regime especial do Ministério da Saúde, que coordena o Sistema Nacional de Vigilância Sanitária com independência administrativa e financeira, estabelecendo normas, propondo, acompanhando, executando as políticas, diretrizes e ações no âmbito de atuação da Vigilância Sanitária.

É importante destacar que as citadas agências reguladoras, apesar de atuarem com maior discricionariedade, não atuam em desconformidade com os princípios constitucionais que norteiam a Administração Pública, principalmente com o princípio da legalidade. $O$ poder normativo das agências reguladoras é outorgado pela Lei que as instituiu e está atrelado aos limites impostos pelo legislador, tornando a atividade administrativa correspondente ao âmbito de atuação da Agência Reguladora mais célere e flexível.

(5) A atuação discricionária da Administração Pública corresponde ao poder conferido ao administrador de optar entre duas ou mais alternativas, legalmente admitidas, quando cabivel tal liberdade de escolha no caso concreto. A escolha no caso se dará por critérios de mérito e sempre deverá ser autorizada e moldada pela Lei.

(6) Bucci, Maria Paula D. Direito Administrativo e Politicas Publicas, cit., p. 40. 


\section{METODOLOGIA}

A metodologia aplicada em nosso trabalho foi a análise de discurso que $^{(7)}$ "tem como objetivo básico realizar uma reflexão geral sobre as condições de produção e apreensão de significação de textos produzidos nos mais diferentes campos" Os textos em questão são sentenças proferidas nas Varas da Fazenda Pública do Estado de São Paulo. Foram pesquisadas as seguintes Varas: $2^{\mathrm{a}}, 3^{\mathrm{a}}, 4^{\mathrm{a}}, 7^{\mathrm{a}}, 8^{\mathrm{a}}, 9^{\mathrm{a}}, 10^{\mathrm{a}}, 11^{\mathrm{a}}, 13^{\mathrm{a}}$ e $14^{\mathrm{a}}$.

$O$ trabalho de pesquisa consistiu em análise de livros de sentenças disponiveis nos respectivos cartórios. A disponibilidade dos livros variou de ano e de número, sendo que a coleta dos documentos foi feita por amostragem e apresentou como resultado 24 sentenças.

Destas, quinze foram julgadas procedentes, enquanto nove tiveram a improcedência como resultado final. Todas as sentenças analisadas são de Mandado de Segurança e apresentaram como impetrados os responsáveis das Secretarias das Administrações Regionais e o Secretário da Saúde do Estado de São Paulo alternadamente. As sentenças coletadas apresentam como impetrantes estabelecimentos comerciais da área farmacêutica.

O trabalho de captação das sentenças perdurou entre os meses de março e setembro de 2002.

A importância da análise de discurso(8) "está na problematização das evidências e explicação do caráter ideológico dessas". No trabalho apresentado, é evidente a disparidade de julgados sobre uma mesma causa de pedir, a saber, a abertura de farmácias e drogarias aos sábados, domingos e feriados fora do horário legal de plantão. Os fundamentos legais que embasam tais decisões apresentam-se em conformidade com os dispositivos legais vigentes. Entretanto, como afirma Minayo $^{(9)}$, não há discurso sem sujeito e nem sujeito sem ideologia, denunciando o encobrimento das formas de dominação política que se manifestam numa razão disciplinar e instrumental.

\section{RESULTADOS E DISCUSSÃO}

Com relação aos resultados da pesquisa, averiguamos que, em sentenças de Mandado de Segurança com o desfecho de IMPROCEDÊNCIA,

(7) MINAYO, M. C. S. O Desafio do Conhecimento: Pesquisa Qualitativa em Saúde. São Paulo-Rio de Janeiro: HUCITEC - ABRASCO, 1992.

(8) Ibidem.

(9) Ibidem. 
suas fundamentações para a não-concessão de liminar estão fulcradas em garantias de direito do consumidor, da livre concorrência, da isonomia em relação a outros estabelecimentos comerciais e da livre iniciativa.

"Surgindo a necessidade do plantão obrigatório, justamente para resguardar e proteger as necessidades do consumidor, também nestes períodos de fraco movimento, resolveu-se, até por falta de opção diversa, limitar a concorrência nestes dias e horários, tornando mais atrativo ou pelo menos não tão sacrificado, o trabalho realizado fora do expediente normal de comércio" - sentença proferida pela $2^{2}$ Vara da Fazenda Pública do Estado de São Paulo(10).

Ou seja, a não-permissão para abertura de farmácias e drogarias fora dos horários previstos em lei não fere nenhuma das garantias apontadas, pois a imposição de horário acarreta necessariamente a permanência de pelo menos um estabelecimento aberto e disponivel à população, garantindo a certeza de atendimento, do lucro do dono do estabelecimento e o resguardo da saúde da população, que foram os bens tutelados pelo legislador ao esboçar os dispositivos legais que impõe tal situação.

Por sua vez, as sentenças de Mandado de Segurança que apresentam decisões de PROCEDÉNCIA têm argumentos fundamentados justamente na premissa de que a lei municipal que impõe tais horários fere princípios constitucionais da isonomia e da livre concorrência, já que, em relação à isonomia, temos a presença cada vez mais marcante de estabelecimentos que comercializam remédios e que estão fora da imposição de horários de plantão. Há a privação de direito líquido e certo do exercício do comércio para as farmácias.

"A impetrante tem direito de vender sua mercadoria em igualdade de condições com os demais estabelecimentos que também comercializam o mesmo produto, independente de qualquer horário" - sentença proferida pela 8 Vara da Fazenda Pública do Estado de São Paulo(11).

Para esses julgados, é interesse público a manutenção de farmácias e drogarias abertas para haver maior comodidade na obtenção desse tipo de produto e maior incentivo à concorrência entre estabelecimentos, o que acarretaria uma competição de preços, resguardando o interesse do consumidor final.

Com relação aos impetrados, temos a presença significativa dos secretários das administrações regionais e, em pouquíssimos casos, a presença do secretário da Saúde. Pelo exposto, é possivel ponderar que a saúde 
em si é colocada em plano inferior aos argumentos de cunho comercial apresentados anteriormente.

A proliferação desmedida de estabelecimentos farmacêuticos acarreta riscos à saúde, como apontado no decorrer do trabalho. Tais efeitos para a saúde não fazem parte do arcabouço cognitivo dos nossos juízes.

O reflexo da supremacia do mercado sobre o resguardo da saúde é evidente e preocupante, e compete à vigilância sanitária de cada município fazer um trabalho de conscientização desses riscos, visando combater o comércio sem ética, que faz da saúde mercadoria e do lucro seu alvo maior.

\section{CONCLUSÃO}

No presente estudo verificou-se a prevalência do Direito Administrativo nos moldes do Direito moderno concebido no final do século XVIII, sob a idéia de Direito regulador, tendência do Direito Administrativo no Estado Contemporâneo.

As sentenças analisadas mostram que a Vigilância Sanitária, como face do Poder Público atuante na fiscalização de farmácias e drogarias, não vem se preocupando em implementar políticas públicas nessa área, desconsiderando que esses estabelecimentos são, sobretudo, estabelecimentos de saúde. A questão não é enfrentada como questão de saúde pública, e sim como puramente comercial. Não existem políticas visando nortear a atuação da Administração Pública neste assunto, que se mostra perdida entre argumentos contrários ao interesse da população, em prol do interesse comercial.

O julgados analisados evidenciam que o Poder Judiciário, assim como a própria Administração Regional do Município de São Paulo, que figura na maioria das sentenças como autoridade impetrada nos Mandados de Segurança estudados, limitam-se a enfrentar a questão unicamente sob o prisma comercial, equiparando, muitas vezes, medicamentos a mercadorias e farmácias e drogarias a supermercados e lojas de conveniência (estabelecimentos que não têm relação alguma com o conceito de estabelecimento de saúde).

\section{REFERÊNCIAS BIBLIOGRÁFICAS}

1. BARROS, José Augusto Cabral. Propaganda de Medicamentos. Atentado à Saúde? São Paulo-Rio de Janeiro: HUCITEC - SOBRAVIME, 1995.

2. BUCCI, Maria Paula Dallari. Direito Administrativo e Políticas Públicas. São Paulo: Saraiva, 2002. 
3. CAPRA, F. O Ponto de Mutação. São Paulo: Cultrix, 1986.

4. DALLARI, Dalmo de Abreu. Elementos da Teoria Geral do Estado. São Paulo: Saraiva, 2000, $21^{\text {a }}$ edição atualizada.

5. MINAYO, M. C. S. O Desafio do Conhecimento: Pesquisa Qualitativa em Saúde. São Paulo-Rio de Janeiro: HUCITEC - ABRASCO, 1992.

6. SEVERINO, Antônio Joaquim. Metodologia do Trabalho Científico. São Paulo: Cortez, 1990, 16 edição. 